OPEN ACCESS

Edited by:

Liang-Yu Chen,

Jiangsu University of Science and

Technology, China

Reviewed by:

Huijun Kang,

Dalian University of Technology, China

Yanfei Wang,

China University of Mining and

Technology, China

Ge Zhou,

Shenyang University of

Technology, China

*Correspondence:

Zhentao Yu

yzt@c-nin.com

Jun Cheng

524161386@qq.com

Specialty section

This article was submitted to

Structural Materials,

a section of the journal

Frontiers in Materials

Received: 03 March 2020

Accepted: 15 April 2020

Published: 06 May 2020

Citation:

Cheng J, Li J, Yu S, Du Z, Zhang X

Gai J, Fan J, Zhang W, Song $H$ and

Yu Z (2020) Room Temperature

Deformation and Superelastic

Behavior of TLM Titanium Alloy Under

Different Solution Conditions.

Front. Mater. 7:114.

doi: 10.3389/fmats.2020.00114

\section{Room Temperature Deformation and Superelastic Behavior of TLM Titanium Alloy Under Different Solution Conditions}

\author{
Jun Cheng ${ }^{1,2 *}$, Jinshan $\mathrm{Li}^{1}$, Sen $\mathrm{Yu}^{2}$, Zhaoxin Du ${ }^{3}$, Xiaoyong Zhang ${ }^{4}$, Jinyang Gai ${ }^{4}$, \\ Jiangkun Fan ${ }^{1}$, Wen Zhang ${ }^{2}$, Hongjie Song ${ }^{2}$ and Zhentao $\mathrm{Yu}^{5 *}$
}

\begin{abstract}
${ }^{1}$ State Key Laboratory of Solidification Processing, Northwestern Polytechnical University, Xi'an, China, ${ }^{2}$ Northwest Institute for Nonferrous Metal Research, Shaanxi Key Laboratory of Biomedical Metal Materials, Xi'an, China, ${ }^{3}$ School of Materials Science and Engineering, Inner Mongolia University of Technology, Hohhot, China, ${ }^{4}$ State Key Laboratory of Powder Metallurgy, Central South University, Changsha, China, ${ }^{5}$ Institute of Advanced Wear and Corrosion Resistant and Functional Materials, Jinan University, Guangzhou, China
\end{abstract}

Metastable $\beta$-type Ti-Nb based alloys are extensively applied in the fields of surgical implantation and wound repair owing to their low elastic modulus, excellent biocompatibility as well as superelastic properties. Based on the d-electron theory, a novel metastable $\beta$-type Ti-25Nb-3Zr-2Sn-3Mo (wt \%) (TLM) alloy was developed using the Bo ( $d$ orbital electron bonding strength) - Md ( $d$ electron bonding energy) diagram. The microstructures and phase constituents of the prepared alloys under different solution conditions were investigated. The unidirectional tensile tests and cyclic loading-unloading experiments were conducted to analyze the mechanical behavior and superelastic behavior. Moreover, the microstructural characteristics near the fracture for the samples under different solution conditions were also investigated. Such results show that $\alpha$ " quenched martensite phase is generated within the equiaxed $\beta$ grains of the TLM alloys which are solution-treated in the $\beta$ or $(\alpha+\beta)$ phase regions. The typical double yielding of the TLM alloys is presented during the deformation at room temperature. The alloy solution-treated at $750^{\circ} \mathrm{C}$ has the strain hardening rate of $\sim 1,100$ $\mathrm{MPa}$ and the uniform elongation of $\sim 32.5 \%$. The stress-induced martensite phase and deformation twins are simultaneously generated in the microstructures of the TLM alloys during the deformation. Such alloys exhibit a certain superelastic effect due to the reverse transformation between the stress-induced martensite $\alpha$ " phase and $\beta$ parent phase during the cyclic loading-unloading at room temperature. Furthermore, the underlying relationship between the properties of the TLM alloys and their microstructures are discussed.

Keywords: TLM alloy, solution treatment, double yielding, superelastic behavior, stress-induced martensite, deformation twins 


\section{INTRODUCTION}

In recent years, metastable $\beta$ type Ti-Nb based titanium alloys have been extensively applied in the fields of surgical implant device, bone tissue repair and artificial joint replacement due to their low elastic modulus, excellent biocompatibility as well as superelastic properties (Miyazaki et al., 2006; Hao et al., 2007, 2012; Sun et al., 2010; Al-Zain et al., 2011; Zhang and Chen, 2019; Zhang et al., 2020). At room temperature, with the decrease in $\beta$ phase stability, the primary deformation mechanisms, in turn, are dislocation slip, deformation twins and stress-induced martensitic (SIM) for $\beta$ titanium alloys during the plastic deformation (Marteleur et al., 2012; Ahmed et al., 2015; Zhang et al., 2017; Mompiou et al., 2018; Rabadia et al., 2019a,b). The multiple design ideas for titanium alloys always involve the interaction of various alloying elements, resulting in various complex microstructures, which leads to the difficulty in determining the specific relationships among the chemical composition, microstructure, mechanical properties of the alloy. The alloy design method of d-electron was developed based on the calculation of molecular orbital of DV (discretevariation)-Xa Cluster. Based on the d-electron theory, the intrinsic relationship between the plastic deformation behavior and $\beta$ phase stability could be predicted by means of Bo ( $\mathrm{d}$ orbital electron bonding strength) - $\mathrm{Md}$ ( $\mathrm{d}$ electron bonding energy) diagram. When the $\mathrm{Md}$ value increases or the Bo value decreases, the $\beta$ phase stability would decrease. Abdel-Hady et al. (2006) plotted the Bo-Md diagram (Md: 2.35 2.60, Bo: 2.78 2.96) based on the existing experimental data. An alloy design criterion, which simultaneously considers the improvement in strength and plasticity of $\beta$ titanium alloys, was proposed based on the Bo-Md diagram (Sun et al., 2013). When certain beta titanium alloys are placed in a particular zone in Bo-Md diagram, the stress-induced martensite transformation, deformation twins as well as dislocation movement would be simultaneously activated. In addition, the strain strengthening effect would be enhanced and hence the room-temperature ductility of $\beta$ titanium alloys would be improved due to the symbiosis and coordination of these deformation mechanisms (Ahmed et al., 2016; Brozek et al., 2016).

In general, the stress-induced martensitic transformation takes place during the deformation of the metastable $\beta$ titanium alloys at room temperature. Therefore, the lower yield strength and higher plasticity at room temperature can be obtained. For instance, the stress-induced martensite transformation would take place in the Ti-Mo binary alloy system. Sun et al. (2013) found that the stress-induced martensite phase is generated at a strain of $0.7 \%$ by investigating the deformation mechanisms of Ti-12Mo (wt\%, the same hereafter) alloy at room temperature. Meanwhile, the increase of the strain results in the increase in the volume fraction of SIM phase. When the content of molybdenum is $<10 \%$, the martensite phase is prone to be induced during the deformation process. On the contrary, if the content of molybdenum is more than $10 \%$, there is no stress-induced martensite phase transformation in the Ti-12Mo alloy. Furthermore, the deformation twinning is another typical deformation mechanism for the $\beta$ titanium alloys (Tobe et al.,
2014). Sun et al. (2017) and Yao et al. (2017) studied the plastic deformation behavior and mechanism of biomedical beta type Ti-24Nb-4Zr-8Sn titanium alloy. The result showed that when the yield strength reaches about $200 \mathrm{MPa}$, the stress-induced martensite phase transformation $(\beta \rightarrow \alpha$ ") were activated at first. In the meantime, the tensile curves also exhibit typical pseudo-elastic behavior. Subsequently, the higher work hardening rate is obtained due to the presence of $\{112\}<111>$ deformation twinning. Therefore, it could be reasonably concluded that for Ti-Nb based (Kim et al., 2006; Yang et al., 2010) and other beta titanium alloys, the stressinduced martensite transformation is one of the primary reasons for the pseudo-elastic deformation behavior as well as lower yield strength and work hardening rate. Moreover, the deformation twinning could be motivated when a small yield stress is obtained during the deformation at room temperature. As such, the phase transformation and deformation mechanisms of the $\beta$ titanium alloys could be controlled via various heat treatments, including solution and aging treatment. However, there are few investigations on the effects of the stressinduced martensite transformation and deformation twinning on the microstructural evolution and deformation behavior of $\beta$ titanium alloys during the room temperature deformation at different solution conditions.

The primary problem is how to improve the biocompatibility and biological safety of the biomedical $\beta$ titanium alloys. To control the microstructures and mechanical properties of $\beta$ titanium alloys using various heat treatment conditions is critical for overcoming the above problems. It plays a significant role in expanding the application and development of biomedical titanium alloys with high performance. A novel near $\beta$ Ti-25Nb-3Zr-2Sn-3Mo (TLM) belongs to the third generation of biomedical titanium alloy. The TLM alloy is independently developed by Northwest Institute for Non-ferrous Metal Research (NIN). According to the calculation formula mentioned in Abdel-Hady et al. (2006), the average Bo and Md of TLM alloy are 2.846 and 2.441, respectively. It could be inferred that the deformation mechanism of TLM alloy mainly consists of deformation twins and stress-induced martensite phase transformation in terms of the Bo-Md diagram (Zhan et al., 2015). Moreover, different solution treatments would have a significant influence on the microstructure and deformation mechanisms of $\beta$ titanium alloys. Currently, most studies on TLM alloys concentrates on processing optimization, surface modification and biocompatibility (Kent et al., 2010; Paladugu et al., 2010; Yu et al., 2011). However, there is few reports on the room-temperature deformation and superelastic behavior of TLM alloys treated by different solution conditions.

The aim of this work was to investigate the microstructures and phase constituents of the TLM alloys solution-treated in the $\beta$ and $(\alpha+\beta)$ phase zone. The unidirectional tensile test at room temperature was conducted to analyze the mechanical behavior of the alloy under different solution conditions as well as the microstructure characteristics near the fracture. The cyclic loading-unloading test was used to understand the superelastic behavior of the TLM alloy undergoing various solution treatments. 


\section{MATERIALS AND EXPERIMENTAL PROCEDURES}

\section{Material Preparation}

Consumable electrode blocks were made from sponge titanium (Grade 0, particle size: $0.83 \sim 12.7 \mathrm{~mm}$ ), sponge zirconium ( $\mathrm{Zr}-$ 1), Ti-32Mo, Ti-60Sn, and Nb-47Ti master alloys by $500 \mathrm{~T}$ oil press. The vacuum consumable arc remelting was repeated three times to ensure the homogeneous composition of ingot. Hence, the high/low density inclusions and composition segregation could be effectively avoided. According to GB/T 3620.1-2016, the principle elements of ingots were measured using $\mathrm{X}$-ray fluorescence spectroscopy (XRF) and LECO 600 gas elemental analyzer. The nominal compositions of TLM alloy ingot is listed in Table 1. The ingot underwent a series of processing including billet forging, hot rolling, hot straightening, machining operation and polishing to obtain bars (with a diameter of $15 \mathrm{~mm}$ ). The beta transus temperature of the TLM alloy used was measured to be about $710^{\circ} \mathrm{C}$. A solution treatment was performed in the $(\alpha$ $+\beta)$ phase region $\left(620\right.$ and $\left.700^{\circ} \mathrm{C}\right)$ and the $\beta$ phase region $(750$ and $800^{\circ} \mathrm{C}$ ) for $1 \mathrm{~h}$ followed by water quenched. The specimens for tensile test were machined from the solution-treated bars according to the standard GB/T 228.1-2010. The unidirectional tensile and cyclic loading-unloading tests were performed using an INSTRON-598X electronic universal material testing machine at room temperature.

\section{Microstructure Characterization}

A wire-cutting electric discharge machining (EDM) was used to machine samples from the tensile specimen. The metallographic samples were subsequently ground, polished, and etched for microstructure observation. A Kroll's solution (10\% hydrofluoric acid, 20\% nitric acid, and 70\% distilled water, in vol \%) was used to etch the samples. The microstructures of samples solution-treated under various solution conditions were observed by optical microscope of Zeiss Axio Vert. A1. The phase constituents of various samples were detected with X-ray diffraction (XRD, BRUKER D8 ADVANCE). Preparation of specimens for transmission electron microscopy (TEM) observation was carried out using mechanically grinding and twin-jet electrolytic polishing technique (equipment: Struers A3). The solution of twin-jet polishing was composed of $50 \mathrm{ml}$ perchloric acid, $300 \mathrm{ml}$ ethanediol, and $500 \mathrm{ml}$ methanol. The disks of $3 \mathrm{~mm}$ in diameter were electrolytic polished at $-40^{\circ} \mathrm{C}$ on the voltage of $20 \mathrm{~V}$. A JEOL 2100 transmission electron microscope with the acceleration voltage of $200 \mathrm{kV}$ was used to analyze and characterize the microstructures of the TLM alloys after tensile deformation.

TABLE 1 | Nominal compositions of TLM alloy ingot used in this work (wt\%).

\begin{tabular}{lcccccccc}
\hline Ti & Zr & Mo & Sn & Nb & C & N & O & H \\
\hline Bal. & 3.05 & 3.05 & 2.05 & 25.5 & 0.010 & 0.003 & 0.049 & 0.0006
\end{tabular}

\section{RESULTS AND DISCIUSSION}

\section{Microstructure and Phase Constituents}

Figure 1 presents the X-ray diffraction patterns of the TLM alloys solution-treated at various temperatures. The diffraction peaks of $\alpha$ " martensite are presented after solution treatment at $620,700,750$, and $800^{\circ} \mathrm{C}$. It indicates that $\alpha "$ martensite phase is generated accompanied by solution treatment and water quenching. Zhang et al. (2013) found that near $\beta$ titanium alloys did not have enough time to complete the $\beta \rightarrow \alpha$ phase transformation due to the rapid cooling rate during solution plus water quenching treatment in super-elastic $\mathrm{Ti}-\mathrm{Nb}-\mathrm{Zr}$ system. The phase transformation is generally completed in the following two modes: (1) the crystal structure itself can not be changed, only the $\beta$ phase forms martensite phase based on the shear effect. (2) If the beta stabilizers in the alloy is relatively high, the beta phase is relatively stable at this condition. After solution treatment plus rapid cooling, a supercooling $\beta$ phase can be generated, and all of them could be retained to room temperature. On the contrary, the stability of $\beta$ phase would decrease due to the lower content of $\beta$ stabilizers. After solution treatment plus rapid cooling, ( $\beta$ $+\alpha$ ") phase can be produced simultaneously. The theoretical value of equivalent is 10.57 for TLM alloys. Compared with other $\beta$-type titanium alloys with high equivalent, the content of $\beta$ stabilizer of the TLM alloy is relatively lower. Therefore, the $\alpha$ " martensite phase would be formed after solution treatment plus water quenching.

Figure 2 presents the metallographic structure for the TLM alloys after solution treatment at $620,700,750$, and $800^{\circ} \mathrm{C} / 1 \mathrm{~h}$ plus water quenching. Figures 2A,B show that after solution treatment at $620^{\circ} \mathrm{C}$, the microstructures of samples mainly consist of primary $\alpha, \alpha$ " martensite, and $\beta$ phases. As the solution temperature increases, the volume fraction of $\alpha$ phase significantly decreases, which finally transforms into $\beta$ phase.

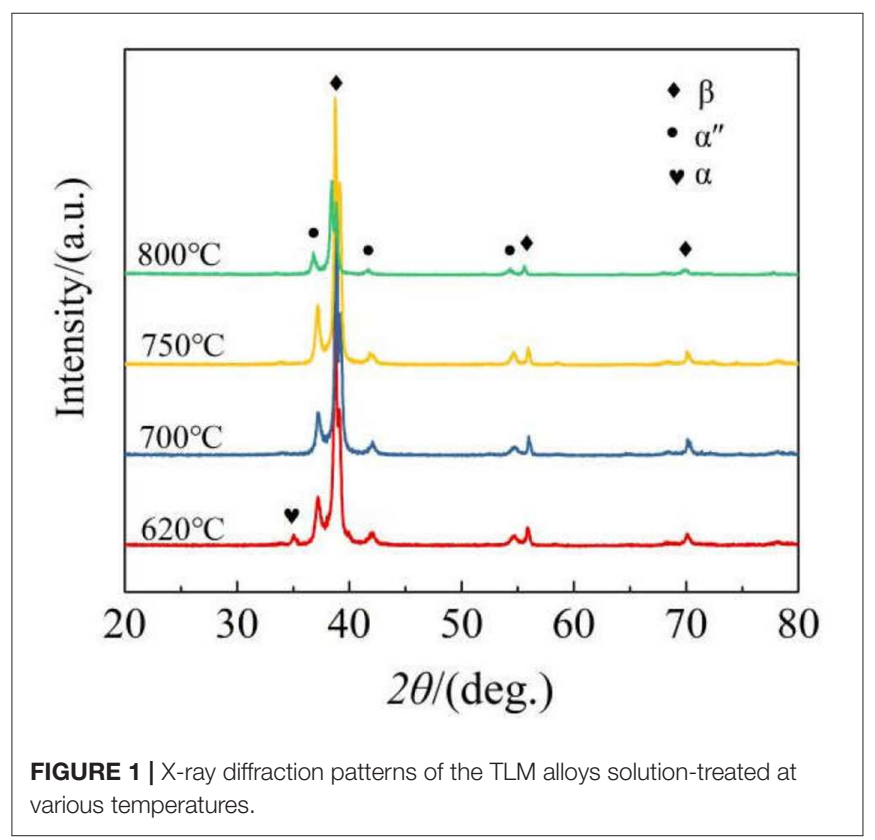



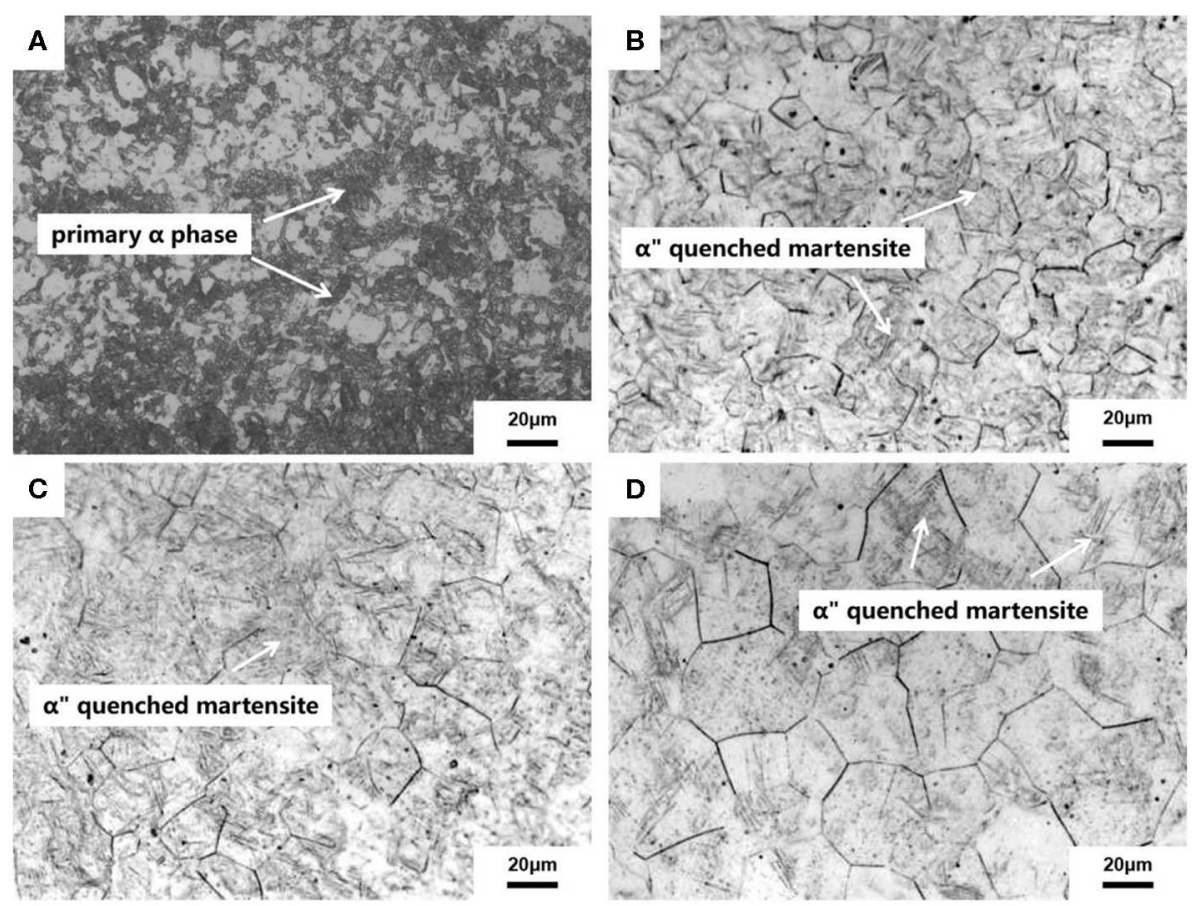

FIGURE 2 | Microstructures of the TLM alloy after solution treatment at: (A) $620^{\circ} \mathrm{C}$; (B) $700^{\circ} \mathrm{C}$; (C) $750^{\circ} \mathrm{C}$; and (D) $800^{\circ} \mathrm{C} / 1 \mathrm{~h}, \mathrm{WQ}$.

When the solution temperature $\left(750\right.$ and $\left.800^{\circ} \mathrm{C}\right)$ increases over the $\beta$ transus temperature, most of primary $\alpha$ phase transforms into $\beta$ phase. Meanwhile, the equiaxed $\beta$ grains are obtained (Figures 2C,D). In addition, the equiaxed $\beta$ grains grow up obviously as the solution temperature increases. From the comparison between Figures 2C,D, it shows that the average grain size is only $\sim 35 \mu \mathrm{m}$ after solution at $750^{\circ} \mathrm{C}$. In comparison, the average size of $\beta$ grains grows up to about $60 \mu \mathrm{m}$ after solution treated at $800^{\circ} \mathrm{C}$.

\section{Double Yielding Effect}

Figure 3 presents the room temperature tensile curves of the TLM alloy solution-treated in $(\alpha+\beta)\left(620\right.$ and $\left.700^{\circ} \mathrm{C}\right)$ and $\beta$ phase region $\left(750\right.$ and $\left.800^{\circ} \mathrm{C}\right)$. It can be seen that the typical double yielding effect is exhibited during the tensile deformation at room temperature. The first yield point is caused by the stress-induced martensite phase transformation. This yield point defined as the stress value corresponding to $0.2 \%$ residual strain is the martensite phase transformation induced stress $\sigma_{\text {SIM }}$ (Kim et al., 2005). In fact, the martensite phase is activated by stress and the slip is induced subsequently during the tensile deformation at room temperature. The stress-strain curves exhibiting a lower level of yielding strength are caused by the easy precipitation of SIM and the deformation twins. As such, the $\beta$ phase transforms into the $\alpha$ phase and the stability of $\beta$ phase would be enhanced after solution treatment in $(\alpha+\beta)$ phase region. In addition, the driving force for $\beta \rightarrow \alpha$ " phase transformation could be reduced during the deformation at room temperature. Therefore, the precipitation fraction of stress-induced $\alpha$ " phase could be

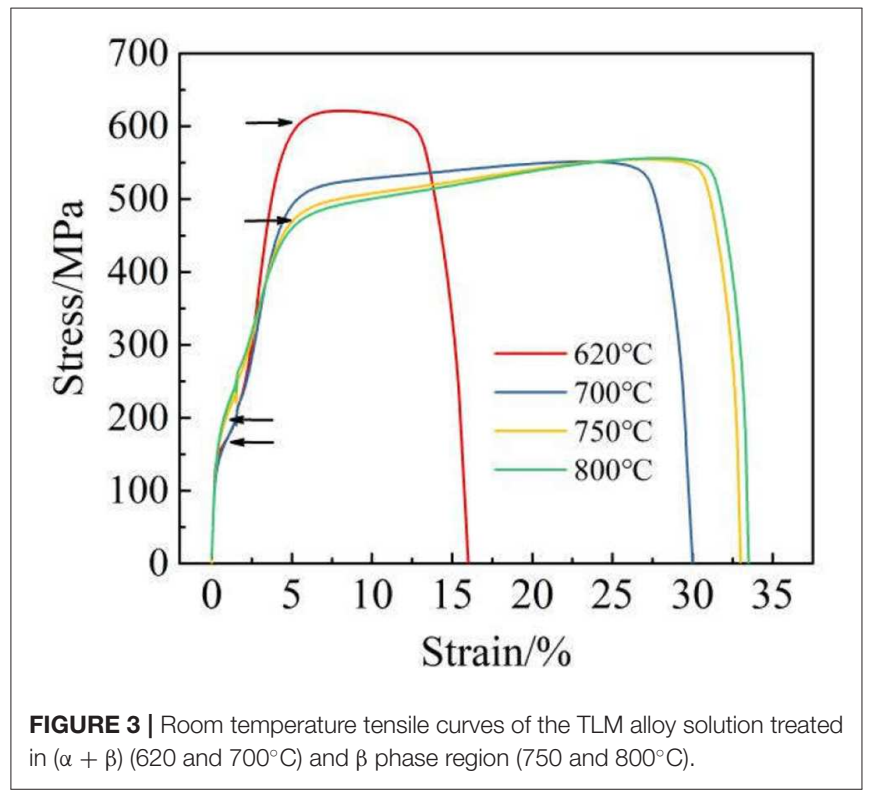

decreased. Therefore, the results show that the tensile strength would be improved due to the generation of $\alpha$ phase.

Figure 4 presents the relationship between the stress induced by martensite phase transformation and the solution temperature of the TLM alloy. It can be seen that the $\sigma_{\text {SIM }}$ is relatively lower $(140 \sim 170 \mathrm{MPa})$ for the sample solution-treated in $(\alpha+\beta)(620$ and $700^{\circ} \mathrm{C}$ ) as compared to the sample solution-treated in $\beta$ phase region $\left(750\right.$ and $\left.800^{\circ} \mathrm{C}\right)$. 
As the solution temperature rises, $\sigma_{\mathrm{SIM}}$ decreases at first and then increases. It is obvious to find that the sample with the minimum $\sigma_{\text {SIM }}(140 \mathrm{MPa})$ is obtained after the solution temperature of $700^{\circ} \mathrm{C}$. It indicates that the amount of $\alpha$ " phase is relatively less after solution treatment at $700^{\circ} \mathrm{C}$ and water quenching. This process results in the easy occurrence of stressinduced martensitic phase transformation in the metastable $\beta$ phase grains during deformation at room temperature. In addition, the stress corresponding to the second yield point is defined as the yield stress $\sigma_{\mathrm{s}}$ before uniform plastic deformation. Figure 5 presents the relationship between the yield stress $\sigma_{\mathrm{s}}$, elongation $\delta$ and solution temperature for the TLM alloy. It indicates that $\sigma_{s}$ gradually decreases with the increase of the solution temperature of the samples. On the contrary, $\delta$ significantly increases for the sample solution-treated in the $(\alpha$ $+\beta)$ phase region $\left(620\right.$ and $\left.700^{\circ} \mathrm{C}\right)$ with the increase of solution

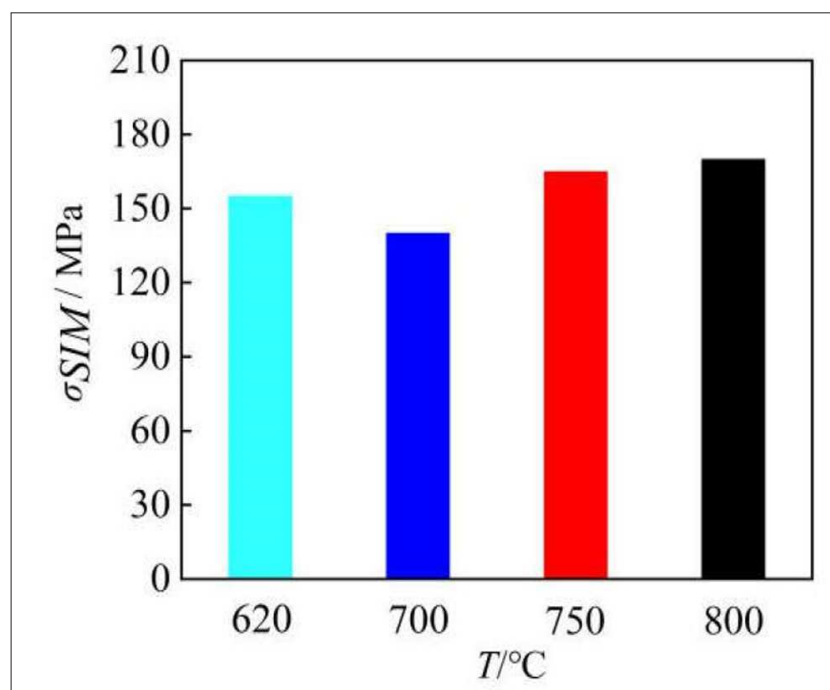

FIGURE 4 | The relationship between the stress induced by martensite phase transformation and the solution temperature of the TLM alloy.

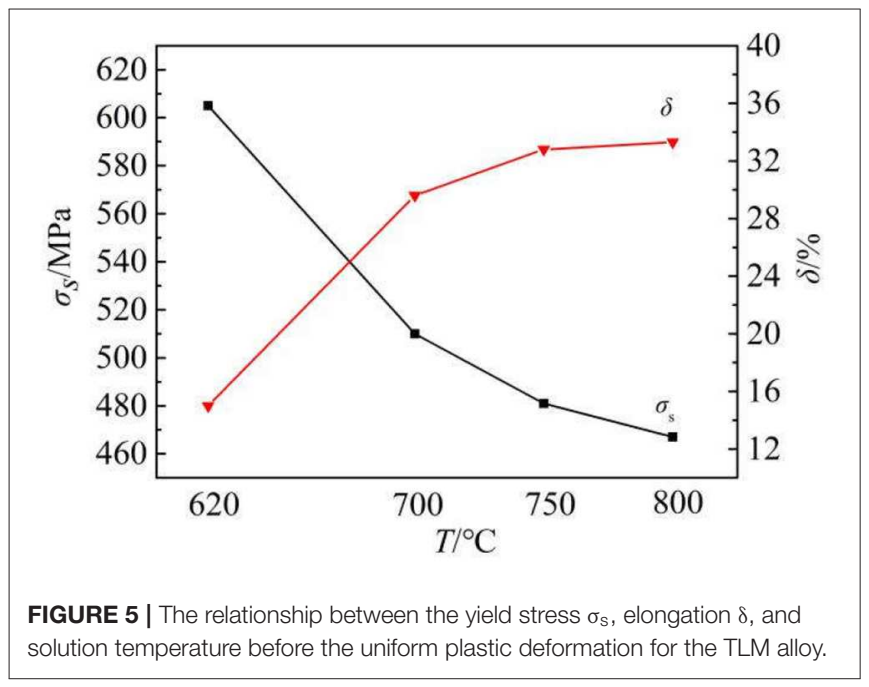

temperature. It is found that the increment of $\delta$ is about $14 \%$ for the sample solution-treated at 620 and $700^{\circ} \mathrm{C}$, respectively. When the solution temperature exceeds $\beta$-transus, the increment of $\delta$ decreases with the increase of the solution temperature. Finally, $\delta$ gradually attains a constant value $(\sim 32.5 \%)$, which represents that the TLM alloy possesses a superior plasticity at room temperature under this condition. This phenomenon is similar to that of Grosdidier and Philippe (2000) studying the deformation behavior at room temperature for $\beta$-CEZ titanium alloys treated at different solution temperatures. The metastable $\beta$ type titanium alloys solution-treated in the $\beta$ phase region are prone to exhibit the double yielding effect during deformation at room temperature. On the contrary, the degree of double yielding effect for the alloy solution-treated in the $(\alpha+\beta)$ phase region is relatively weak. When the alloys are solution-treated in the $(\alpha+\beta)$ phase region, the larger difference between the solution

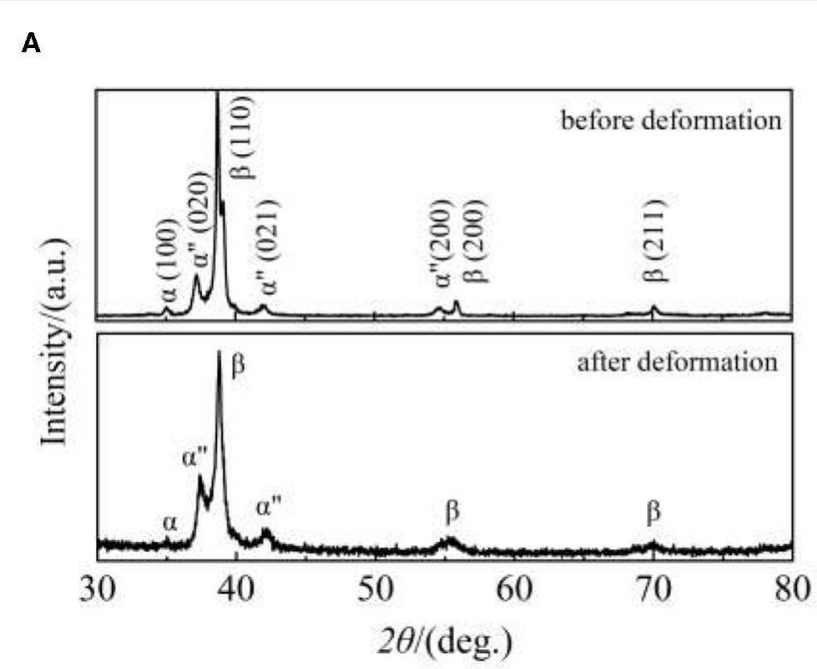

B

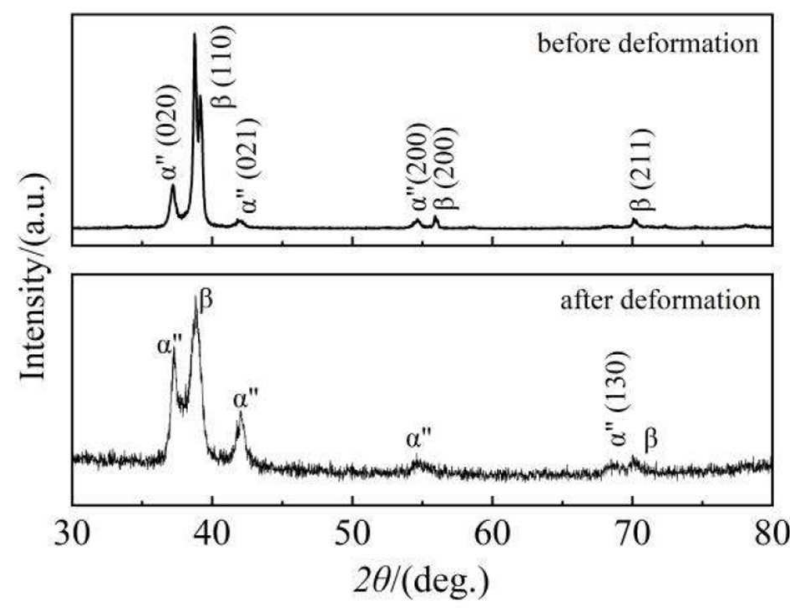

FIGURE 6 | X-ray diffraction profiles near the fracture surface before and after tensile deformation of the TLM alloy (A) solution treated in the $(\alpha+\beta)\left(620^{\circ} \mathrm{C}\right)$; (B) $\beta$ phase region $\left(750^{\circ} \mathrm{C}\right)$. 
temperature and $\beta$-transus is, the greater driving force for the precipitation of the primary $\alpha$ phase would be needed. There are a large amount of nucleation sites presenting in the $\beta$ matrix, which is favorable for the nucleation and precipitation of the primary $\alpha$ phase. Meanwhile, the remaining $\beta$ phase becomes more stable. The driving force for the phase transformation $(\beta \rightarrow \alpha$ ") during the deformation at room temperature decreases, leading to a significant reduction in the volume fraction of $\alpha$ "phase.

Figure 6 displays the XRD patterns near the fracture surface before and after tensile deformation of the TLM alloy solution-treated in the $(\alpha+\beta)\left(620^{\circ} \mathrm{C}\right)$ and $\beta$ phase regions $\left(750^{\circ} \mathrm{C}\right)$. It can be seen that when the specimen is tensiledeformed until fracture takes place, although the diffraction peaks of $\alpha$ " phase are still presented, there is a significant difference in the intensities of diffraction peaks and peak positions compared with the undeformed counterpart. The reason is that the quenched martensite $\alpha$ " phase undergoes micro-deformation along a specific crystallographic orientation (preferred orientation) during tensile deformation. It is also accompanied by stress-induced martensitic transformation, which is the result of synergy effect between phase transformation and texture evolution during plastic deformation (Mantani et al., 2002).

\section{Strain Hardening Effect}

Figure 7 shows the curve of the strain hardening rate (SHR) for the TLM alloy after solution treatment at $750^{\circ} \mathrm{C}$. It indicates that the strain hardening rate is as high as $1,100 \mathrm{MPa}$ in the work hardening stage. In addition, there are two typical stages represented by stage I and stage II in the curve during the tensile deformation. Stage $\mathrm{I}$ is the transitional stage from the elastic deformation to plastic deformation. At first, the value of SHR decreases sharply. Secondly, it slowly rises and then decreases after reaching the maximum value. The deformation at this stage is mainly dominant by stress-induced martensite and dislocation slip since the dislocations easily cut through the martensite phases during deformation. The enhancement of

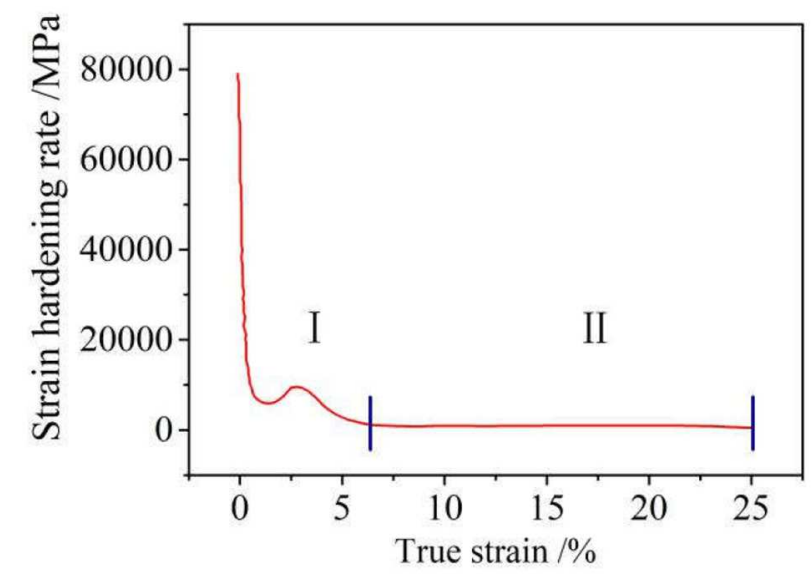

FIGURE 7 | The curve of the strain hardening rate for the TLM alloy solution treated at $750^{\circ} \mathrm{C}$. strain hardening rate mainly results from deformation twins. Meanwhile, the necking behavior is improved to a higher strain due to the generation of the martensite. Furthermore, the strain hardening effect might be associated with the refinement of $\beta$ grains since new and deformed twins with high misorientation boundaries are continuously formed, resulting in a decrease in the dislocation mean free path. In fact, the SIM transformation take participate in the strain hardening behavior as well.

Figure 8 presents the TEM microstructures of the stressinduced martensite and deformation twins as well as the selected area electron diffraction (SAED) patterns of stress-induced martensite for the TLM alloy solution-treated at $750^{\circ} \mathrm{C}$ after tensile deformation at room temperature. Figure $\mathbf{8 A}$ shows that the stress-induced martensite $\alpha$ " phase precipitates as lath from $\beta$ matrix. Moreover, there is a small amount of dislocation pile
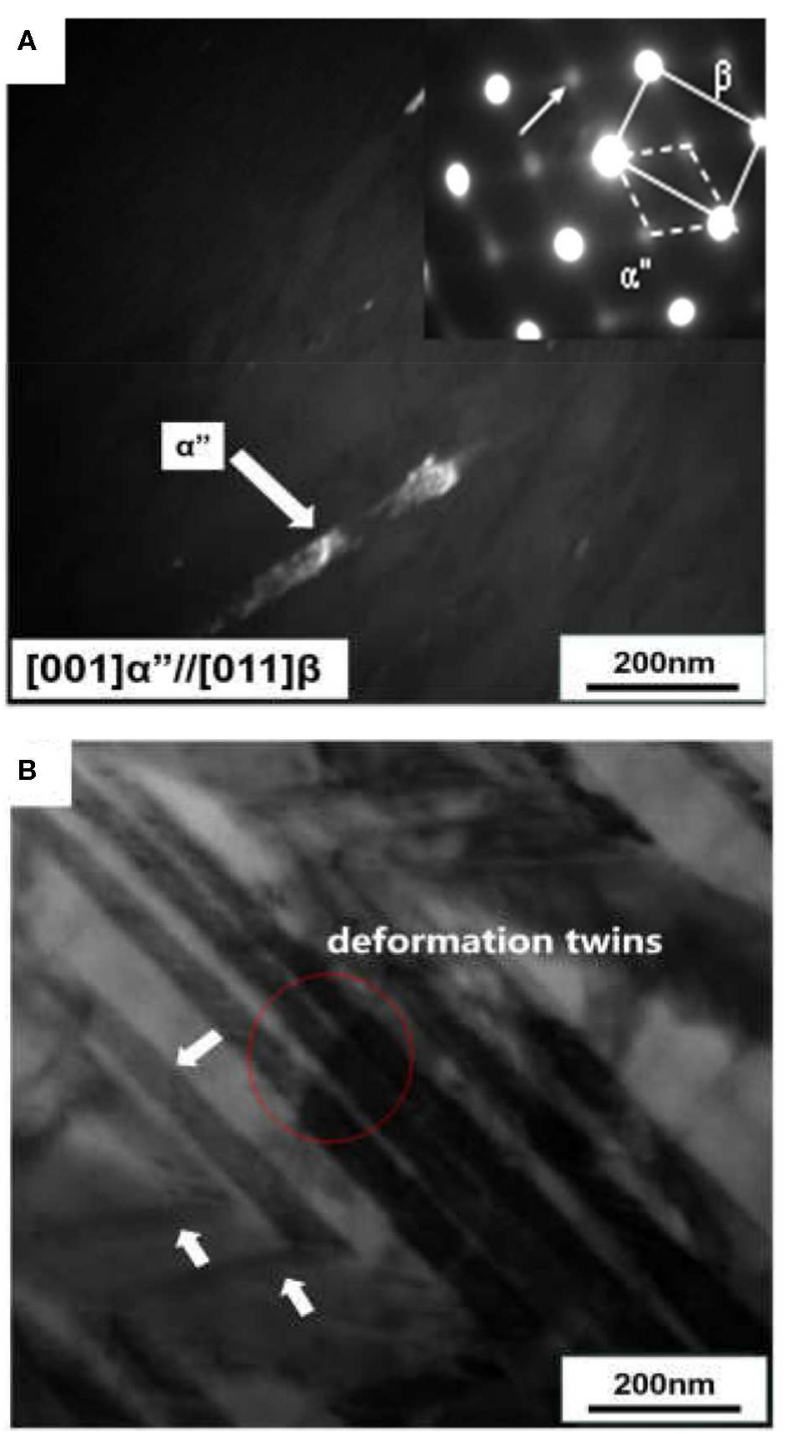

FIGURE 8 | TEM microstructures of the TLM alloy solution treated at $750^{\circ} \mathrm{C}$ after tensile deformation at room temperature: (A) stress-induced martensite and its selected area electron diffraction (SAED) pattern; (B) deformation twins. 


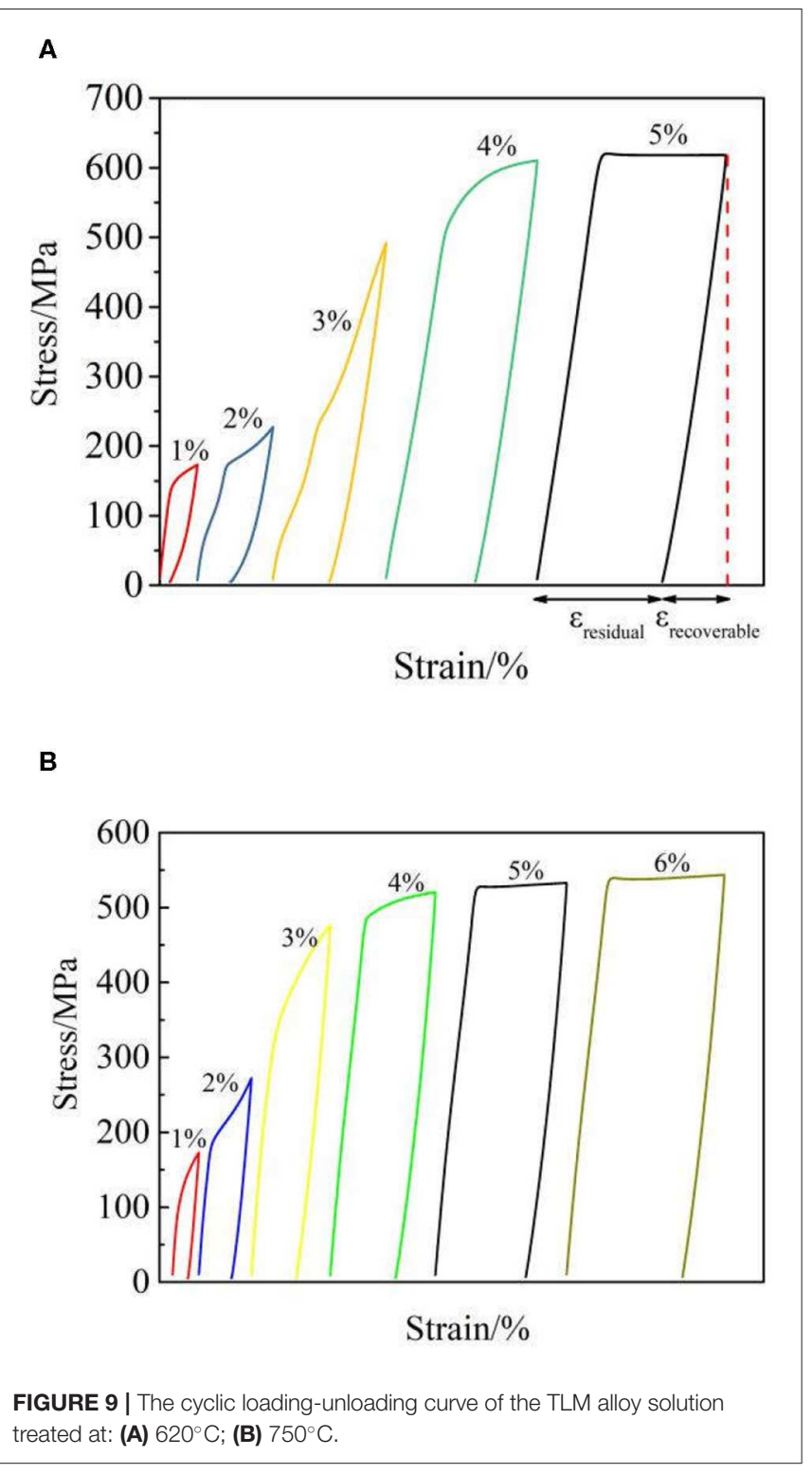

up inside the $\alpha$ " grain. In the stage II range of the SHR curve, deformation twins with different orientations are formed during the deformation process before the true strain reaching $25 \%$ (Figure 8B). Therefore, strain hardening rate can be maintained at a steady state under the coordinated deformation between the stress-induced martensite and deformation twins.

\section{Superelastic Behavior}

When the deformation, which is much larger than the elastic limit, is applied to a $\beta$ type metastable titanium alloy. Once the load is removed and the deformed alloy subsequently returns to its original shape. Such a phenomenon is defined as superelastic behavior. The stress-induced martensite phase transformation takes place during plastic deformation at room temperature. The superelastic behavior of metallic material can be described by the cyclic loading-unloading curves. Figure 9 shows the cyclic

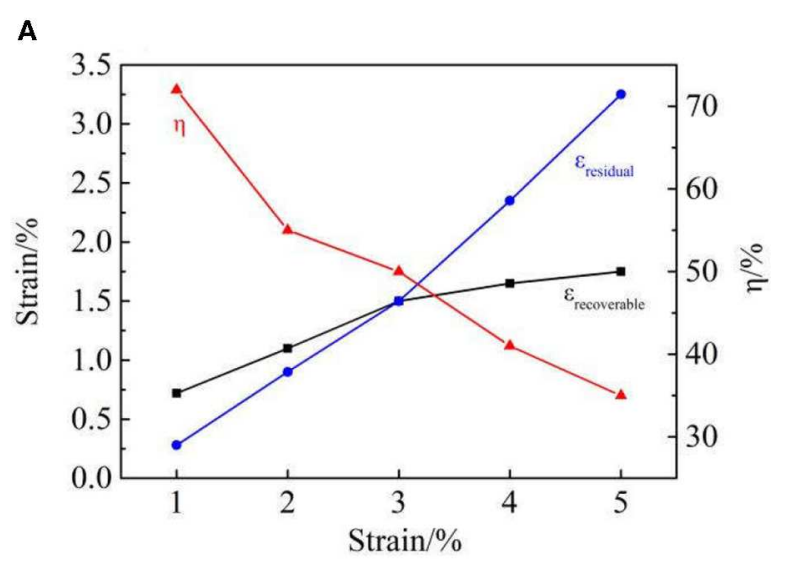

B

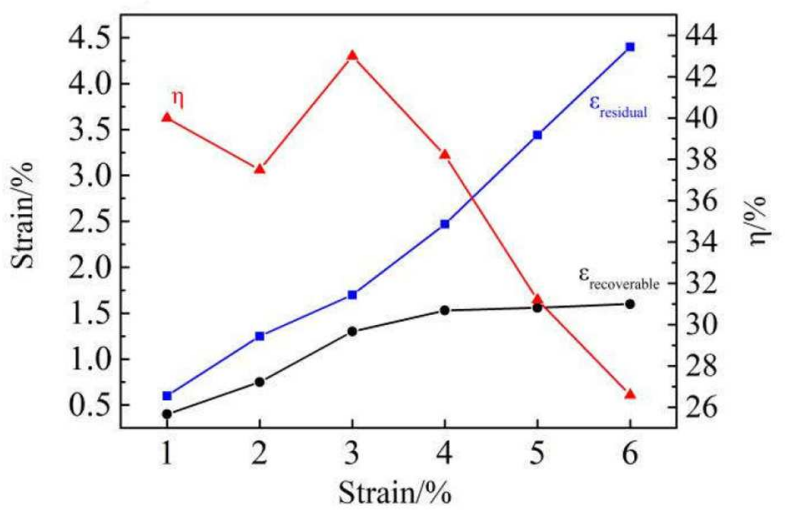

FIGURE 10 | Curves of the residual strain ( $\left.\varepsilon_{\text {residual }}\right)$, recoverable strain $\left(\varepsilon_{\text {recoverable }}\right)$, recovery rate $(\eta)$ and preloading strain of the TLM alloy solution treated at: (A) $620^{\circ} \mathrm{C}$; (B) $750^{\circ} \mathrm{C}$.

loading-unloading curves of the TLM alloy solution-treated in $(\alpha+\beta)\left(620^{\circ} \mathrm{C}\right)$ and $\beta$ phase regions $\left(750^{\circ} \mathrm{C}\right)$. It can be seen that the curve exhibits a non-linear recovery characteristic when the preloading strain is $1 \sim 3 \%$. The alloy exhibits a certain superelastic effect because there is a reverse transformation relationship between the stress-induced martensitic $\alpha$ " phase and the $\beta$ parent phase during the unloading of applied load. In addition, the double yielding effect gradually weakens until it disappears and the corresponding residual strain increases with the increase of preloading strain. One can conclude that the TLM alloy solution-treated in the $\beta$ phase region has better roomtemperature ductility than the counterpart solution-treated in the $(\alpha+\beta)$ phase region. Therefore, the sample solutiontreated in the $(\alpha+\beta)$ phase region reveal failure fracture when the preloading strain is $6 \%$. Plenty of the quenching martensite $\alpha$ " phase grains are presented within the $\beta$ matrix after solution treatment plus water quenching, which reduces the number of the stress-induced martensite phase precipitates under small strain condition, resulting in a reduction in the superelastic properties. 
Figure 10 represents the curves of the residual strain $\left(\varepsilon_{\text {residual }}\right)$, recoverable strain $\left(\varepsilon_{\text {recoverable }}\right)$, recovery rate $(\eta)$, and preloading strain of the TLM alloy solution-treated in $(\alpha+\beta)\left(620^{\circ} \mathrm{C}\right)$ and $\beta$ phase regions $\left(750^{\circ} \mathrm{C}\right)$. First, the recoverable strain slowly increases and then gradually tends to be steady with the increase of preloading strain. Meanwhile, the residual strain increases significantly. In contrast, the recovery rate gradually reduces with the increase of the preloading strain. A comparison between Figures 10A,B shows that the TLM alloy solution-treated at $620^{\circ} \mathrm{C}$ has relatively high residual strain and recoverable strain since more martensite $\alpha$ " phases are produced in the $\beta$ matrix after solution treatment plus water quenching. The stressinduced martensite phase precipitates would be reduced at a small strain, resulting in a reduction in the superelastic properties. The double yielding effect gradually weakens with the increase of preloading strain during the cyclic loading-unloading tests at room temperature. Previous studies (Min et al., 2013) showed that the stress-induced martensite phase generated at a low strain could not achieve reversible phase transformation with the increase of preloading strain, leading to the irreversible recovery of deformation twins. The driving force for martensite transformation gradually increases with the accumulation of the stress-induced martensite variant and deformation twins during the subsequent loading process, causing the increase of the double yielding effect barrier and the reduction in the $\eta$ value.

\section{CONCLUSIONS}

(1) The $\alpha$ " quenched martensite phases are generated within the equiaxed $\beta$ grains for the TLM alloy solution-treated in the $\beta$ and $(\alpha+\beta)$ phase regions. The TLM alloy exhibits a typical double yielding effect during the deformation at room temperature.

(2) The TLM alloy has the work hardening rate of $\sim 1,100$ $\mathrm{MPa}$ and the uniform elongation of $\sim 32.5 \%$ after solution treatment in the $\beta$ phase region $\left(750^{\circ} \mathrm{C}\right)$, which is a

\section{REFERENCES}

Abdel-Hady, M., Hinoshita, K., and Morinaga, M. (2006). General approach to phase stability and elastic properties of $\beta$-type Ti-alloys using electronic parameters. Scr. Mater. 55, 477-480. doi: 10.1016/j.scriptamat.2006.04.022

Ahmed, M., Wexler, D., Casillas, G., Ivasishin, O. M., and Pereloma, E. V. (2015). The influence of $\beta$ phase stability on deformation mode and compressive mechanical properties of $\mathrm{Ti}-10 \mathrm{~V}-3 \mathrm{Fe}-3 \mathrm{Al}$ alloy. Acta Mater. 84, 124-135. doi: 10.1016/j.actamat.2014.10.043

Ahmed, M., Wexler, D., Casillas, G., Savvakin, D. G., and Pereloma, E. V. (2016). Strain rate dependence of deformation-induced transformation and twinning in a metastable titanium alloy. Acta Mater. 104, 190-200. doi: 10.1016/j.actamat.2015.11.026

Al-Zain, Y., Kim, H. Y., Koyano, T., Hosoda, H., Nam, T. H., and Miyazaki, S. (2011). Anomalous temperature dependence of the superelastic behavior of Ti-Nb-Mo alloys. Acta Mater. 59, 1464-1473. doi: 10.1016/j.actamat.2010. 11.008

Brozek, C., Sun, F., Vermaut, P., Millet, Y., Lenain, A., Embury, D., et al. (2016). A $\beta$-titanium alloy with extra high strain-hardening rate: design and mechanical properties. Scr. Mater. 114, 60-64. doi: 10.1016/j.scriptamat.2015. 11.020 better comprehensive performance for biomedical implants application. It is also accompanied by the formation of stressinduced martensite phases and deformation twins.

(3) The TLM alloy exhibits a certain superelastic effect because there is a reverse transformation between the stress-induced martensitic $\alpha$ " phase and the $\beta$ parent phase during the cyclic loading-unloading at room temperature.

\section{DATA AVAILABILITY STATEMENT}

The datasets generated for this study are available on request to the corresponding author.

\section{AUTHOR CONTRIBUTIONS}

JC carried out the article writing. JL carried out the technical guidance. SY carried out the vacuum arc remelting (VAR) of TLM alloy ingot. ZD carried out the forging of ingot. $\mathrm{XZ}$ carried out the unidirectional tensile testing. JG performed the preparation of metallographic specimens. JF performed the cyclic loading-unloading testing. WZ performed the rolling of bar. HS performed the mechanical processing of specimens. ZY performed the technical reviewing.

\section{FUNDING}

This work was financially supported by the National Natural Science Foundation of China (Nos. 51901193 and 51861029), Key Research and Development Program of Shaanxi (Program Nos. 2019GY-151, 2019GY-178 and 2019GY-251), Science and Technology Plan Project of Weiyang District in Xi'an City (201905), and State Key Laboratory of Powder Metallurgy, Central South University, Changsha, China (621011823). JC was the leader of the funding.
Grosdidier, T., and Philippe, M.-J. (2000). Deformation induced martensite and superelasticity in a $\beta$-metastable titanium alloy. Mater. Sci. Eng. A 291, 218-223. doi: 10.1016/S0921-5093(00)00921-7

Hao, Y. L., Li, S. J., Prima, F., and Yang, R. (2012). Controlling reversible martensitic transformation in titanium alloys with high strength and low elastic modulus. Scr. Materialia 67, 487-490. doi: 10.1016/j.scriptamat.2012.06.011

Hao, Y. L., Li, S. J., Sun, S. Y., Zheng, C. Y., and Yang, R. (2007). Elastic deformation behaviour of $\mathrm{Ti}-24 \mathrm{Nb}-4 \mathrm{Zr}-7.9 \mathrm{Sn}$ for biomedical applications. Acta Biomater. 3, 277-286. doi: 10.1016/j.actbio.2006.11.002

Kent, D., Wang, G., Yu, Z., and Dargusch, M. S. (2010). Pseudoelastic behaviour of a $\beta \mathrm{Ti}-25 \mathrm{Nb}-3 \mathrm{Zr}-3 \mathrm{Mo}-2 \mathrm{Sn}$ alloy. Mater. Sci. Eng. A 527, 2246-2252. doi: 10.1016/j.msea.2009.11.059

Kim, H. Y., Ikehara, Y., Kim, J. I., Hosoda, H., and Miyazaki, S. (2006). Martensitic transformation, shape memory effect and superelasticity of Ti-Nb binary alloys. Acta Mater. 54, 2419-2429. doi: 10.1016/j.actamat.2006.01.019

Kim, J. I., Kim, H. Y., Inamura, T., Hosoda, H., and Miyazaki, S. (2005). Shape memory characteristics of $\mathrm{Ti}-22 \mathrm{Nb}-(2-8) \mathrm{Zr}$ (at.\%) biomedical alloys. Mater. Sci. Eng. A 403, 334-339. doi: 10.1016/j.msea.2005.05.050

Mantani, Y., Takemoto, Y., Hida, M., and Sakakibara, A. (2002). Formation of $\alpha$ "martensite and $\{332\}<113>$ twin during tensile deformation in Ti-40 mass\% Nb alloy. JPN Int. Met. 66, 1022-1029. doi: 10.2320/jinstmet1952.66.10_1022 
Marteleur, M., Sun, F., Gloriant, T., Vermaut, P., Jacques, P. J., and Prima, F. (2012). On the design of new $\beta$-metastable titanium alloys with improved work hardening rate thanks to simultaneous TRIP and TWIP effects. Scr. Mater. 66, 749-752. doi: 10.1016/j.scriptamat.2012.01.049

Min, X., Chen, X., Emura, S., and Tsuchiya, K. (2013). Mechanism of twinninginduced plasticity in $\beta$-type Ti-15Mo alloy. Scr. Mater. 69, 393-396. doi: 10.1016/j.scriptamat.2013.05.027

Miyazaki, S., Kim, H. Y., and Hosoda, H. (2006). Development and characterization of Ni-free Ti-base shape memory and superelastic alloys. Mater. Sci. Eng. A 438, 18-24. doi: 10.1016/j.msea.2006.02.054

Mompiou, F., Tingaud, D., Chang, Y., Gault, B., and Dirras, G. (2018). Conventional vs harmonic-structured $\beta$-Ti-25Nb-25Zr alloys: a comparative study of deformation mechanisms. Acta Mater. 161, 420-430. doi: 10.1016/j.actamat.2018.09.032

Paladugu, M., Kent, D., Wang, G., Yu, Z., and Dargusch, M. S. (2010). Strengthening of cast $\mathrm{Ti}-25 \mathrm{Nb}-3 \mathrm{Mo}-3 \mathrm{Zr}-2 \mathrm{Sn}$ alloy through precipitation of $\alpha$ in two discrete crystallographic orientations. Mater. Sci. Eng. A 527, 6601-6606. doi: 10.1016/j.msea.2010.06.075

Rabadia, C. D., Liu, Y.-J., Chen, L.-Y., Jawed, S. F., Wang, L.-Q., Sun, H., et al. (2019a). Deformation and strength characteristics of Laves phases in titanium alloys. Mater. Des. 179:107891. doi: 10.1016/j.matdes.2019.107891

Rabadia, C. D., Liu, Y.-J., Zhao, C.-H., Wang, J.-C., Jawed, S. F., Wang, L.-Q., et al. (2019b). Improved trade-off between strength and plasticity in titanium based metastable beta type Ti-Zr-Fe-Sn alloys. Mater. Sci. Eng. A 766:138340. doi: 10.1016/j.msea.2019.138340

Sun, F., Nowak, S., Gloriant, T., Laheurte, P., Eberhardt, A., and Prima, F. (2010). Influence of a short thermal treatment on the superelastic properties of a titanium-based alloy. Scr. Mater. 63, 1053-1056. doi: 10.1016/j.scriptamat.2010.07.042

Sun, F., Zhang, J. Y., Marteleur, M., Gloriant, T., Vermaut, P., Laillé, D., et al. (2013). Investigation of early stage deformation mechanisms in a metastable $\beta$ titanium alloy showing combined twinning-induced plasticity and transformation-induced plasticity effects. Acta Mater. 61, 6406-6417. doi: 10.1016/j.actamat.2013.07.019

Sun, F., Zhang, J. Y., Vermaut, P., Choudhuri, D., Alam, T., Mantri, S. A., et al. (2017). Strengthening strategy for a ductile metastable $\beta$ titanium alloy using low-temperature aging. Mater. Res. Lett. 5, 547-553. doi: 10.1080/21663831.2017.1350211

Tobe, H., Kim, H. Y., Inamura, T., Hosoda, H., and Miyazaki, S. (2014). Origin of $\left\{\begin{array}{lll}3 & 3 & 2\end{array}\right\}$ twinning in metastable $\beta$-Ti alloys. Acta Mater. 64, 345-355. doi: 10.1016/j.actamat.2013.10.048
Yang, Y., Wu, S. Q., Li, G. P., Li, Y. L., Lu, Y. F., Yang, K., et al. (2010). Evolution of deformation mechanisms of $\mathrm{Ti}-22.4 \mathrm{Nb}-0.73 \mathrm{Ta}-2 \mathrm{Zr}-1.34 \mathrm{O}$ alloy during straining. Acta Mater. 58, 2778-2787. doi: 10.1016/j.actamat.2010. 01.015

Yao, T., Du, K., Wang, H., Huang, Z., Li, C., Li, L., et al. (2017). In situ scanning and transmission electron microscopy investigation on plastic deformation in a metastable $\beta$ titanium alloy. Acta Mater. 133, 21-29. doi: 10.1016/j.actamat.2017.05.018

Yu, S., Yu, Z., Wang, G., Han, J., Ma, X., and Dargusch, M. S. (2011). Biocompatibility and osteoconduction of active porous calcium-phosphate films on a novel $\mathrm{Ti}-3 \mathrm{Zr}-2 \mathrm{Sn}-3 \mathrm{Mo}-25 \mathrm{Nb}$ biomedical alloy. Colloids Surf. B 85, 103-115. doi: 10.1016/j.colsurfb.2011.02.025

Zhan, H., Zeng, W., Wang, G., Kent, D., and Dargusch, M. (2015). On the deformation mechanisms and strain rate sensitivity of a metastable $\beta \mathrm{Ti}-\mathrm{Nb}$ alloy. Scr. Mater. 107, 34-37. doi: 10.1016/j.scriptamat.2015.05.014

Zhang, J., Sun, F., Hao, Y., Gozdecki, N., Lebrun, E., Vermaut, P., et al. (2013). Influence of equiatomic $\mathrm{Zr} / \mathrm{Nb}$ substitution on superelastic behavior of Ti-Nb-Zr alloy. Mater. Sci. Eng. A 563, 78-85. doi: 10.1016/j.msea.2012. 11.045

Zhang, L.-C., and Chen, L.-Y. (2019). A review on biomedical titanium alloys: recent progress and prospect. Adv. Eng. Mater. 21:1801215. doi: 10.1002/adem.201801215

Zhang, L.-C., Chen, L.-Y., and Wang, L.-Q. (2020). Surface modification of titanium and titanium alloys: technologies, developments and future interests. Adv. Eng. Mater. 22:1901258. doi: 10.1002/adem.201901258

Zhang, M., Li, Y.-N., Zhang, F.-C., Wang, X.-B., Chen, L.-Y., and Yang, Z.-N. (2017). Effect of annealing treatment on the microstructure and mechanical properties of a duplex Zr-2.5 Nb alloy. Mater. Sci. Eng. A. 706, 236-241. doi: 10.1016/j.msea.2017.08.107

Conflict of Interest: The authors declare that the research was conducted in the absence of any commercial or financial relationships that could be construed as a potential conflict of interest.

Copyright (C) 2020 Cheng, Li, Yu, Du, Zhang, Gai, Fan, Zhang, Song and Yu. This is an open-access article distributed under the terms of the Creative Commons Attribution License (CC BY). The use, distribution or reproduction in other forums is permitted, provided the original author(s) and the copyright owner(s) are credited and that the original publication in this journal is cited, in accordance with accepted academic practice. No use, distribution or reproduction is permitted which does not comply with these terms. 